\title{
SIMPLIFICANDO A EPIGENÉTICA DA HETEROQUELIA PARA ALUNOS DO ENSINO FUNDAMENTAL
}

\author{
Vale, V.F.V. ${ }^{1,}$; Moraes, S.A.S.N. ${ }^{\text {; }}$ Sequerra, E.B. ${ }^{2}$; Freire, F.A.M. ${ }^{1}$ \& Alencar, C.E.R.D. ${ }^{3}$ \\ ${ }^{1}$ Universidade Federal do Rio Grande do Norte (UFRN), Campus Natal, Laboratório de Fauna Aquática. \\ ${ }^{2}$ Universidade Federal do Rio Grande do Norte (UFRN), Campus Natal. Instituto do Cérebro. \\ ${ }^{3}$ Universidade do Estado do Rio Grande do Norte (UERN), Campus Mossoró.
}

*Autor correspondente: valeriaecolgia@gmail.com

O ensino dos conceitos evolutivos ainda é um desafio para os educadores. As descobertas mais recentes da biologia evolutiva, como a epigenética, sendo o ambiente capaz de introduzir mudanças fenotípicas e estas mudanças serem transgeracionais, é um desafio ainda maior. Como a epigenética está modificando a definição de evolução, precisam os de modelos para explicar mecanismos epigenéticos para o ensino básico. O objetivo deste trabalho foi simplificar e aproximar temas evolutivos complexos, como a epigenética, para alunos do ensino fundamental tomando como organismo-modelo os crustáceos Decapoda. A lateralidade das quelas em Decapoda pode ser determinada genética ou epigeneticamente. Foi realizado uma revisão de literatura sobre a determinação da lateralidade em Decapoda e transcrito para a linguagem infantil. Como resultado foi elaborado um texto de divulgação com a seguinte abordagem: Sabia que crustáceos podem ser destros ou canhotos? Você já quebrou o braço direito e teve que escrever com a mão esquerda? Ou o contrário? Seus pais são destros ou canhotos? Quantos amigos você conhece que são canhotos? Você sabia que na natureza existem animais destros e canhotos? Crustáceos como camarões ou caranguejos podem ser destros ou canhotos. A determinação disto pode ser genética ou por sinal ambiental. Por exemplo, os caranguejos violinistas quando jovens se tornam destros ou canhotos e isto se permanece independente de quantas vezes sua pinça pode ser retirada. Em outros casos perder ou machucar uma das pinças levam à mudança de destro para canhoto, como, por exemplo, em camarões-de-estalo. Os mecanismos epigenéticos podem ser explicados em processos triviais aos seres vivos, como a lateralidade ou destreza dos apêndices especializados. Em crustáceos decápodes isso pode ser mais evidente e usado de forma caricata em ilustrações dos experimentos e discussões sobre o tema. A divulgação do material finalizado será de grande importância para o ensino da síntese moderna e herança epigenética seguindo as diretrizes curriculares brasileiras para os $3^{\circ} \mathrm{e} 4^{\circ}$ ciclos do ensino fundamental.

Palavras-chave: assimetria, Decapoda, eco-evo-devo, ensino, síntese evolutiva estendida. 